\title{
Evaluating uncertainty in sensor networks for urban air pollution insights
}

Daniel R. Peters et al.

Correspondence to: Daniel R. Peters (dpeters@edf.org)

The copyright of individual parts of the supplement might differ from the article licence. 


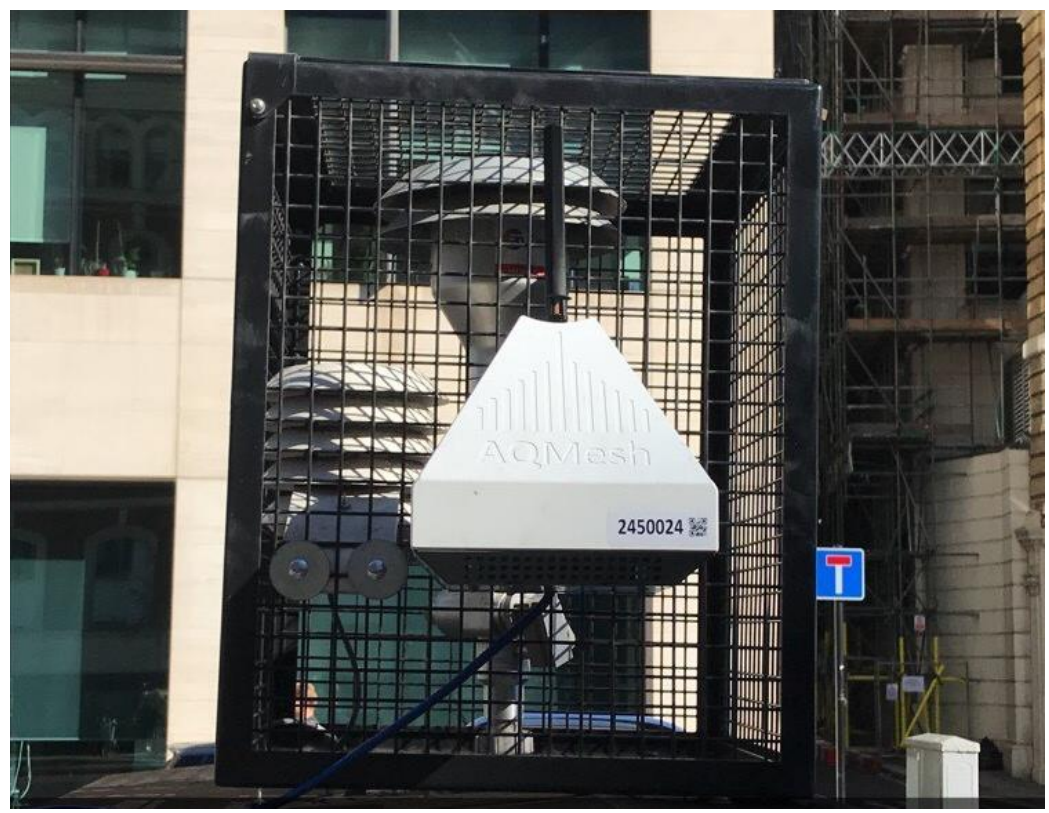

Figure S1: Image of example reference site collocation with a BL device installed at a London reference monitoring station in September 2018.
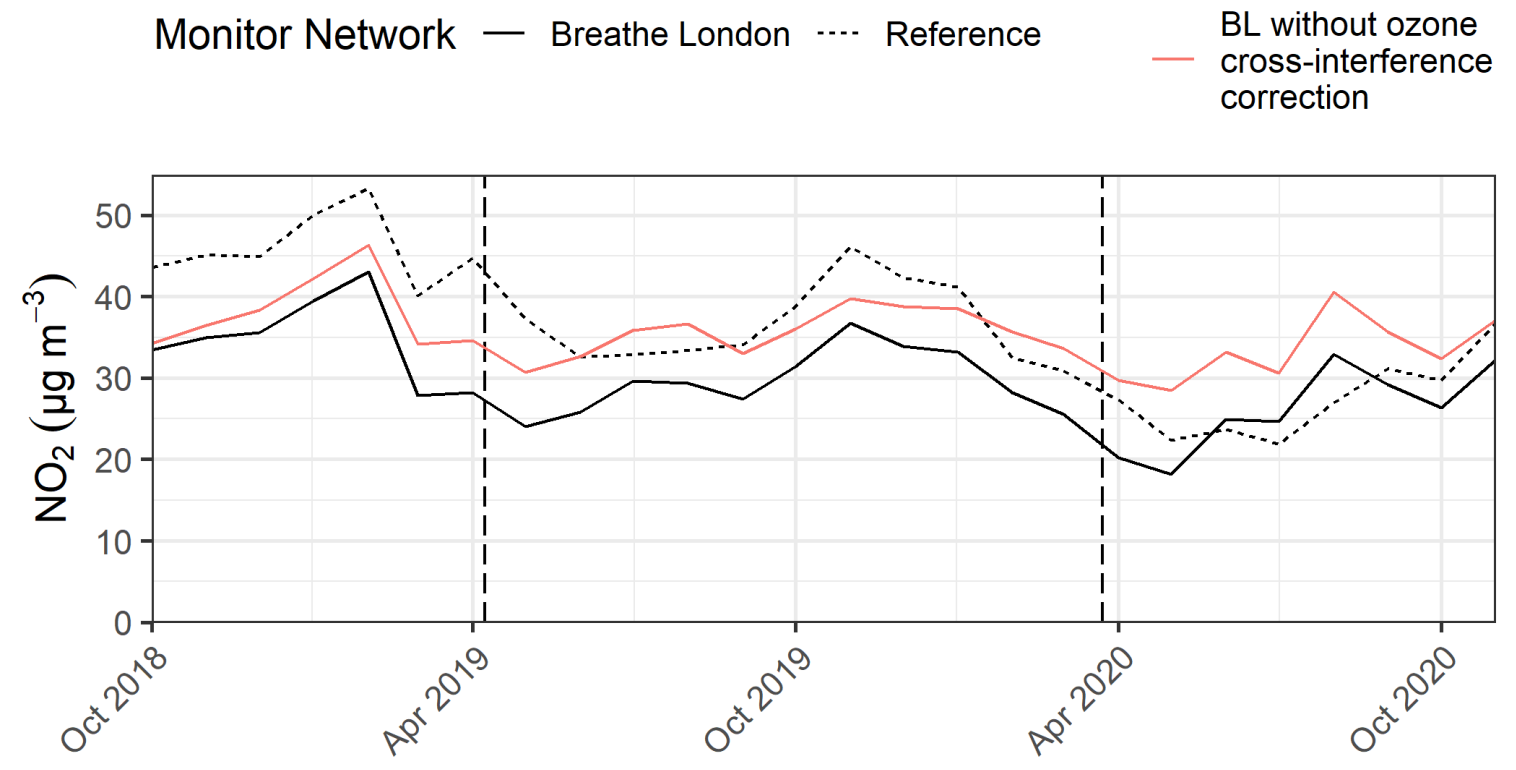

Figure S2: Network monthly mean timeseries comparing BL $(n=100)$ and London reference $(n=105)$ networks. This is the same as top panel of Fig. 4 except red solid line is data without time-dependent ozone cross-interference correction (Sect. 2.3.2). Vertical lines denote Ultra Low Emission Zone (ULEZ) start date (8 April 2019) and the start of the first Covid-19 lockdowns (23 March 2020). 

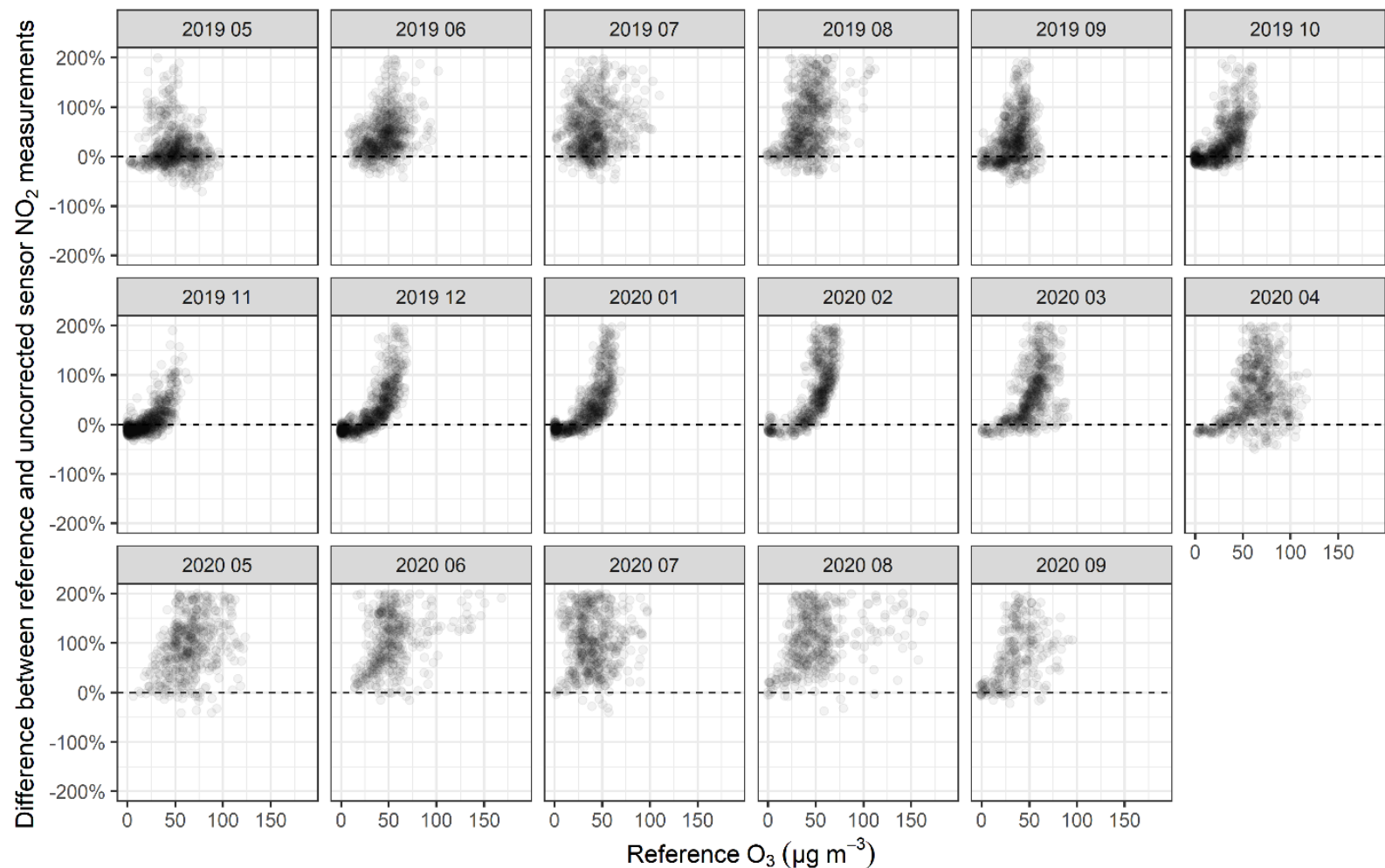

$0 \quad 50100 \quad 150$

Figure S3: Monthly scatterplot of sensor percent bias without an ozone cross-interference correction applied vs. reference ozone measurements for a 17-month collocation of a BL sensor (Unit 83) at the SK6 (Elephant and Castle) LAQN reference site.

Percent bias calculated as (uncorrected sensor NO2 measurement - reference measurement) / reference measurement. 

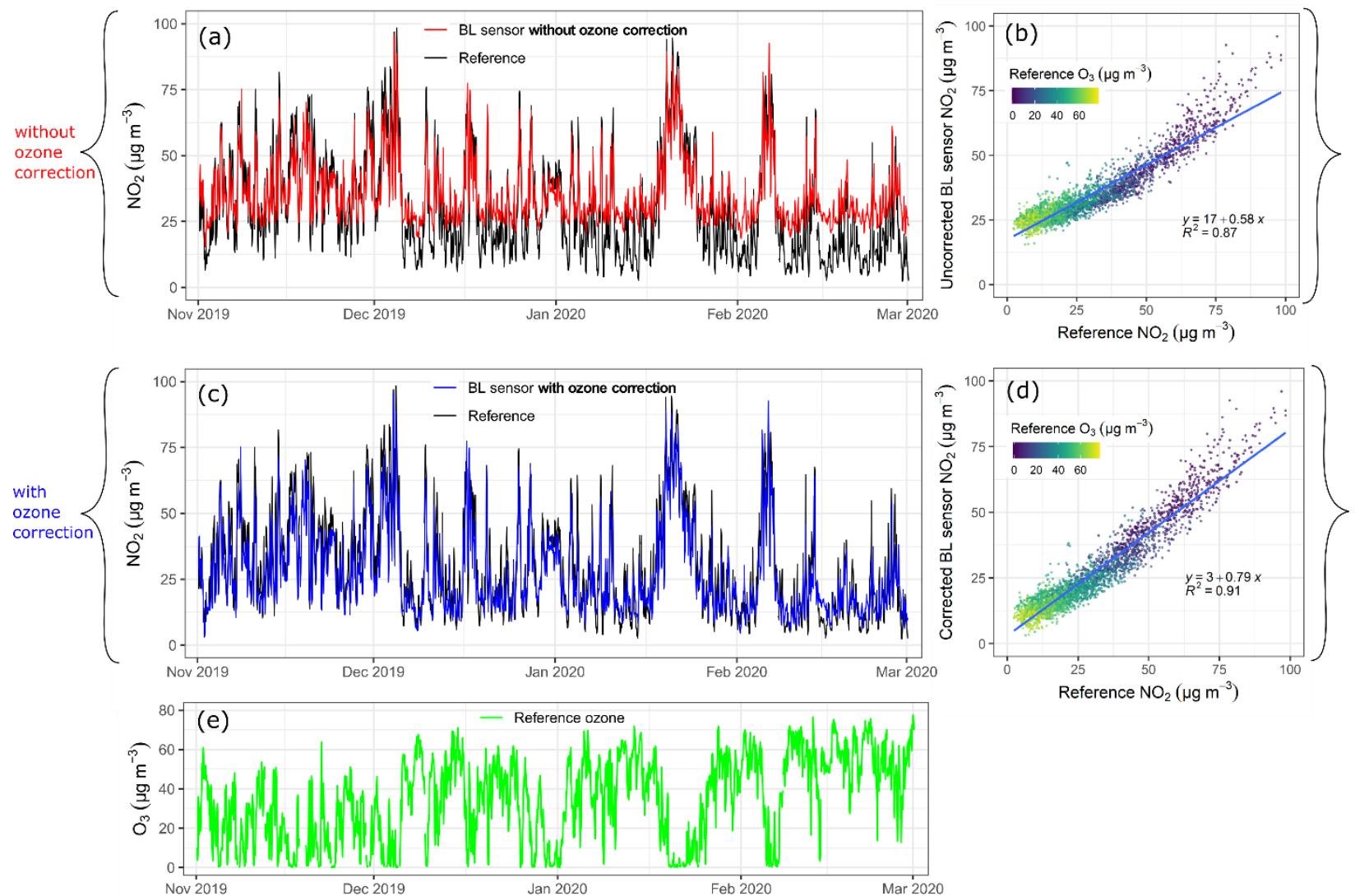

Figure S4: Time series and scatter plots of a BL sensor (Unit 83) at the SK6 (Elephant and Castle) LAQN reference site. (a) hourly timeseries and (b) scatter plot of $\mathrm{BL}$ sensor $\mathrm{NO}_{2}$ without ozone cross-interference correction compared to reference $\mathrm{NO}_{2}$. (c) hourly timeseries and (d) scatterplot of $\mathrm{BL}$ sensor $\mathrm{NO}_{2}$ with ozone cross-interference correction compared to reference $\mathrm{NO}_{2}$. BL sensor data in panels (a) - (d) was calibrated using linear regression against the reference instrument during a two-week period in May 2019, with (c \& d) and without (a \& b) an ozone cross-interference correction. (e) Reference $\mathrm{O}_{3}$ at collocation site (SK6). Points in scatter plots (b) and (d) are colored by reference $\mathrm{O}_{3}$ concentration, and a regression line and equation are shown to emphasize the large positive intercept in the absence of the correction. Ozone-corrected sensor data in panel (c) is a subset of data that was presented in Figure 3 of the manuscript. 


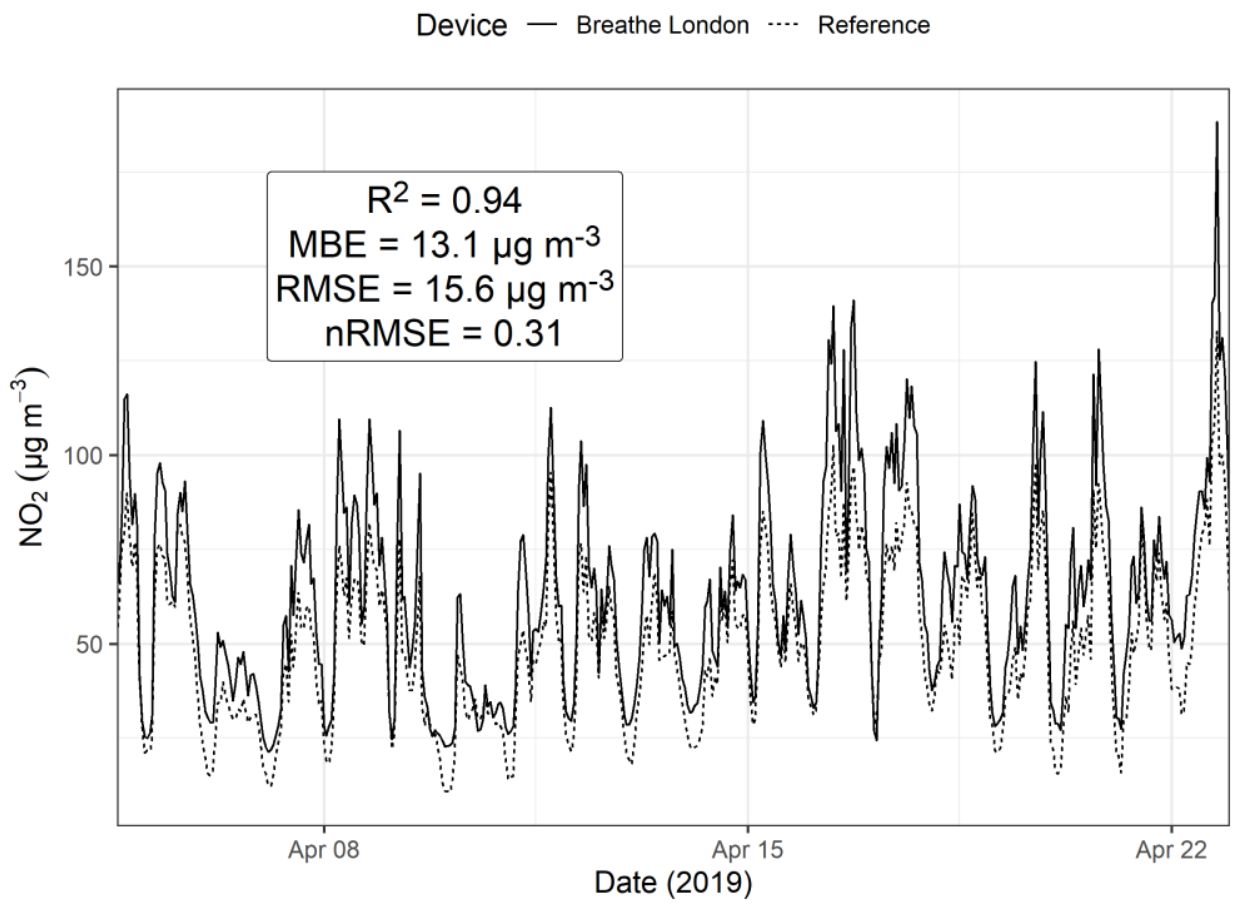

Figure S5: Example April 2019 reference collocation analysis result for BL sensor 2046150 at Camden, Swiss Cottage (CD1) reference site.

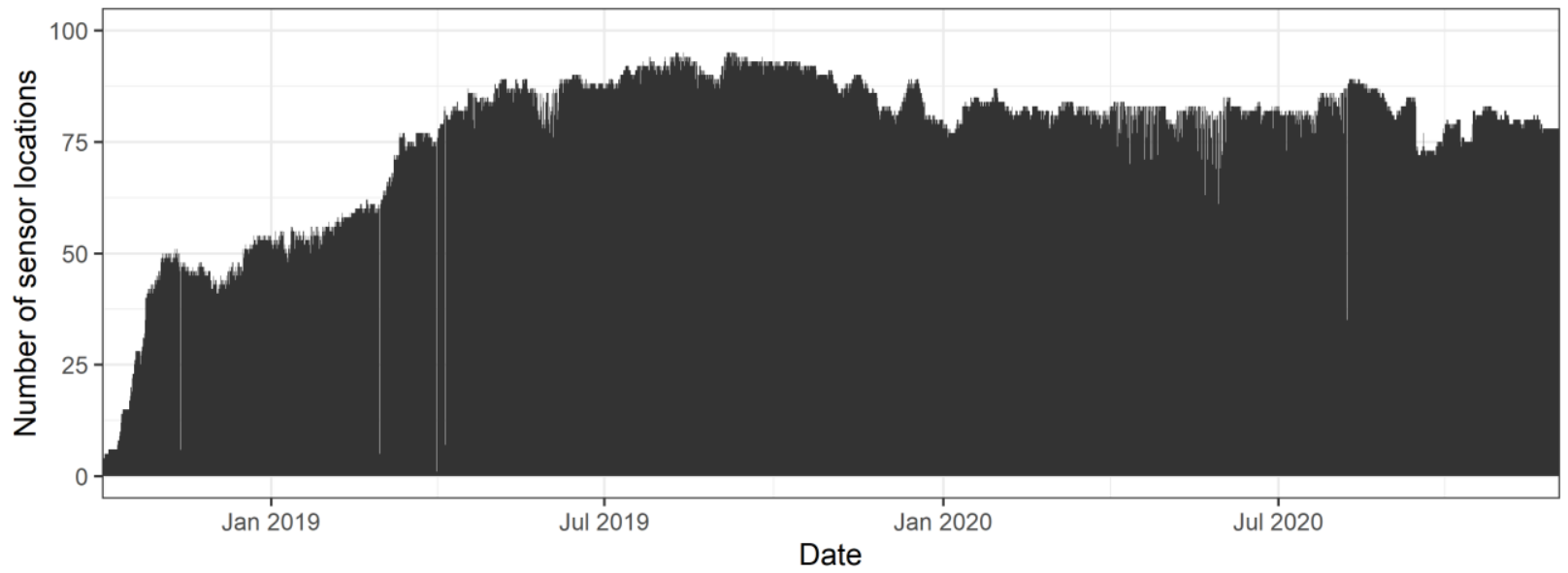

Figure S6: Number of $\mathrm{BL} \mathrm{NO}_{2}$ sensor locations with valid, calibrated measurement at each hour during the campaign. The total inventory of sensors available to the project was 116, which included an original inventory of 100, a set of six provided by the University of Cambridge for network QA/QC and primarily reserved for transfer standard collocations, and a set of 10 provided by Greater London Authority (GLA) in the second year of the project. 


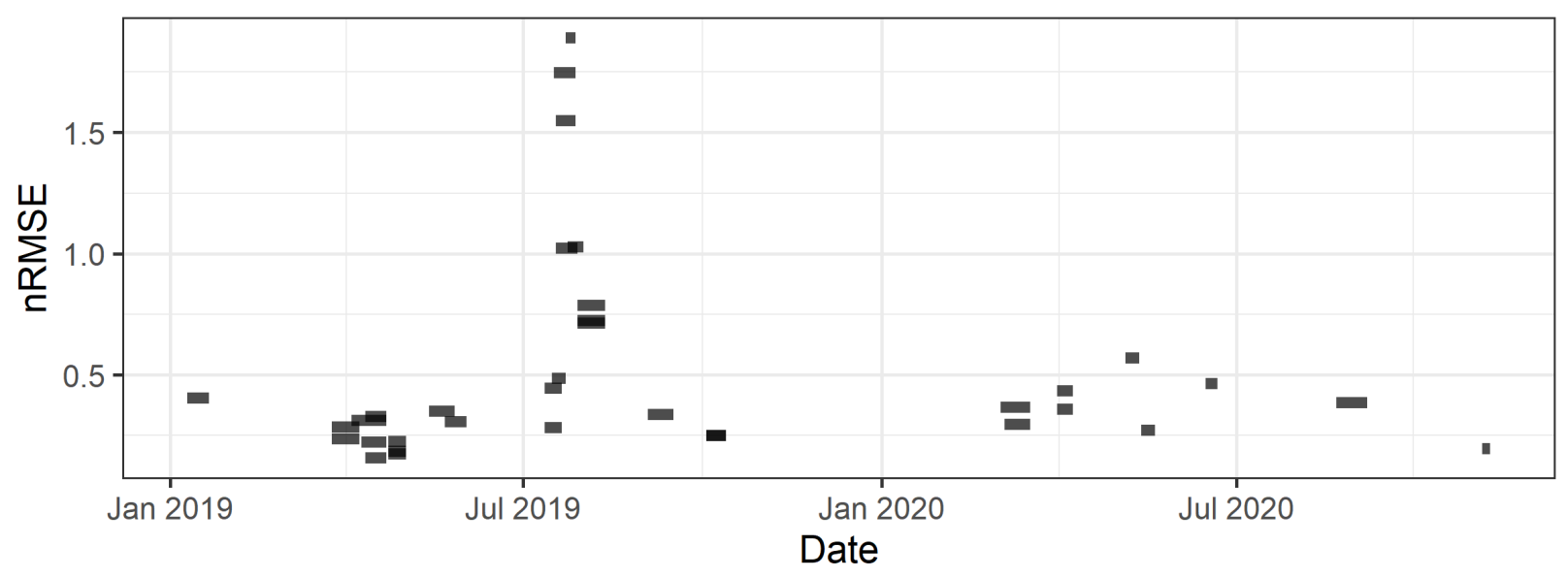

Figure S7: Normalized RMSE of calibrated hourly sensor measurements compared to reference measurements during collocations. Individual collocation uncertainty results are black lines, which extend from the start date to the end date of the collocation from which the uncertainty of the calibrated sensor was quantified.

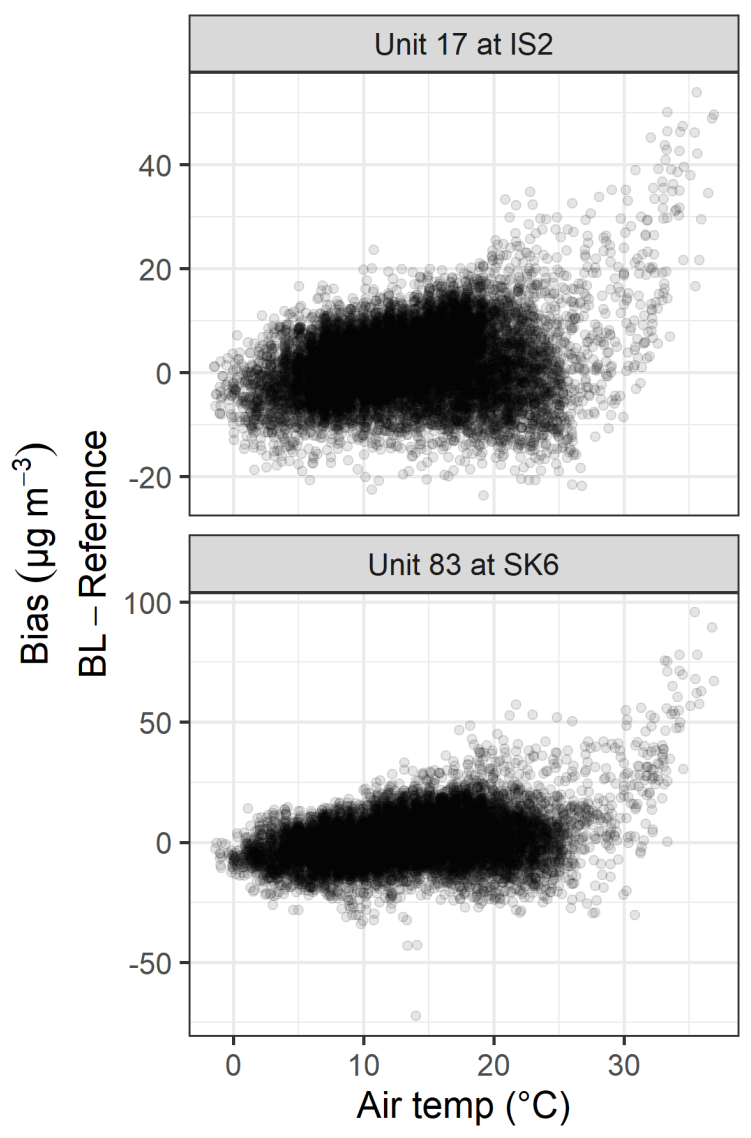

Figure S8: Bias of hourly $\mathrm{NO}_{2}$ measurements by BL sensors 17 (top) and 83 (bottom) compared to collocated reference monitors Islington, Holloway Road (IS2; top) and Southwark, Elephant and Castle (SK6; bottom) compared to ambient air temperature $\left({ }^{\circ} \mathrm{C}\right)$ at London Heathrow Airport during two long-term collocations. Note that y axis scales are different for the two graphs. 


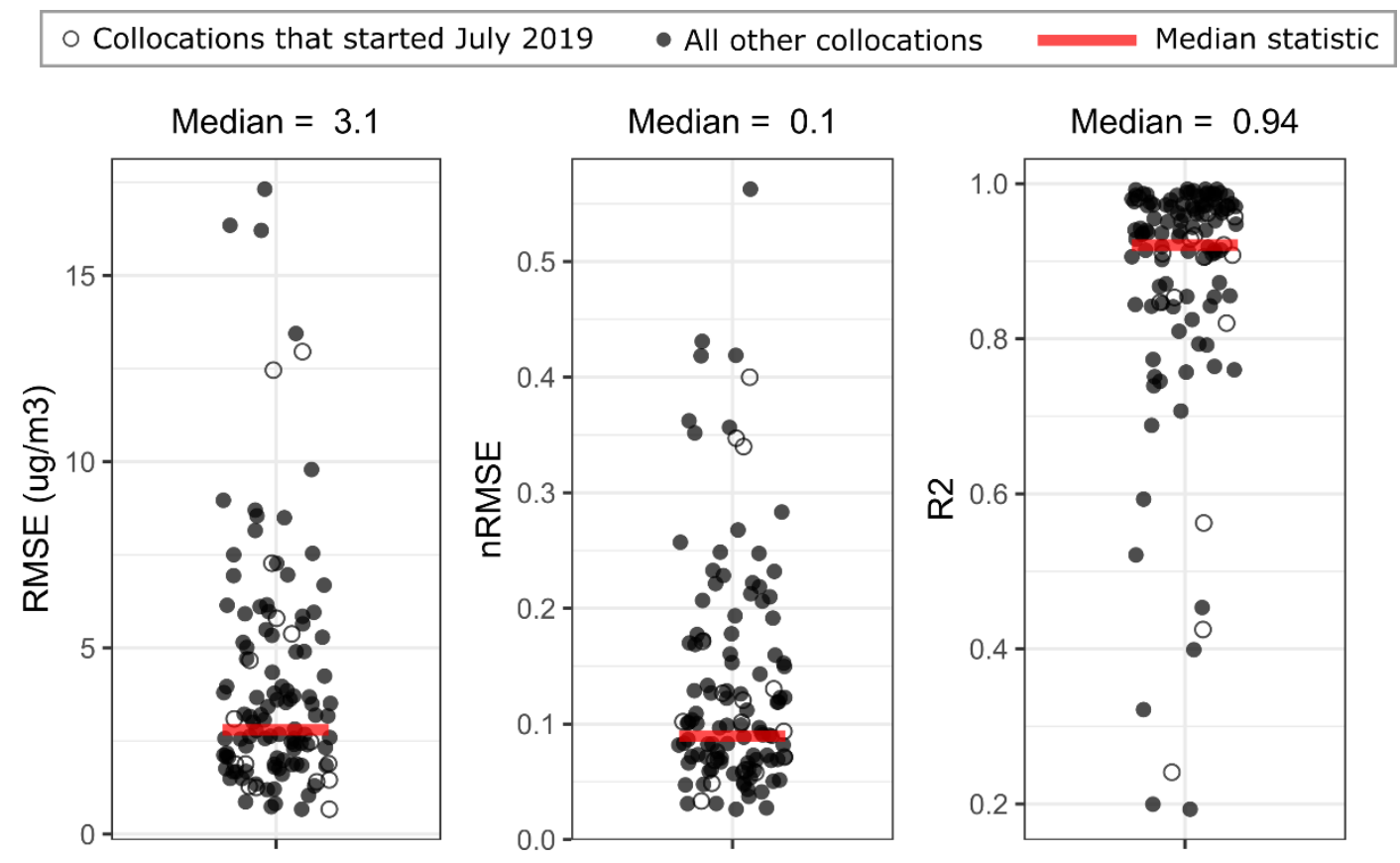

Figure S9: Precision of $\mathrm{NO}_{2}$ sensors during "transfer standard" collocations ( $\left.\mathrm{n}=118\right)$ of two AQMesh units. In each collocation, the candidate sensor timeseries was scaled against the auxiliary or "transfer" device using the linear regression gain and offset result from that collocation (Section 2.3.1) before statistics were calculated. The results represent the random error between sensors when bias has been effectively eliminated by calibration. Unfilled circles are collocations that started in July 2019 during periods of elevated temperatures $(n=16)$. Statistics calculated from hourly measurements (eq. 1-4). Note that 11 collocations that did not meet statistical $\mathrm{R}^{2}$ and nRMSE criteria (Sect. 2.3.1) would have been excluded as invalid in our QA/QC procedures and would not have been used for calibration. 


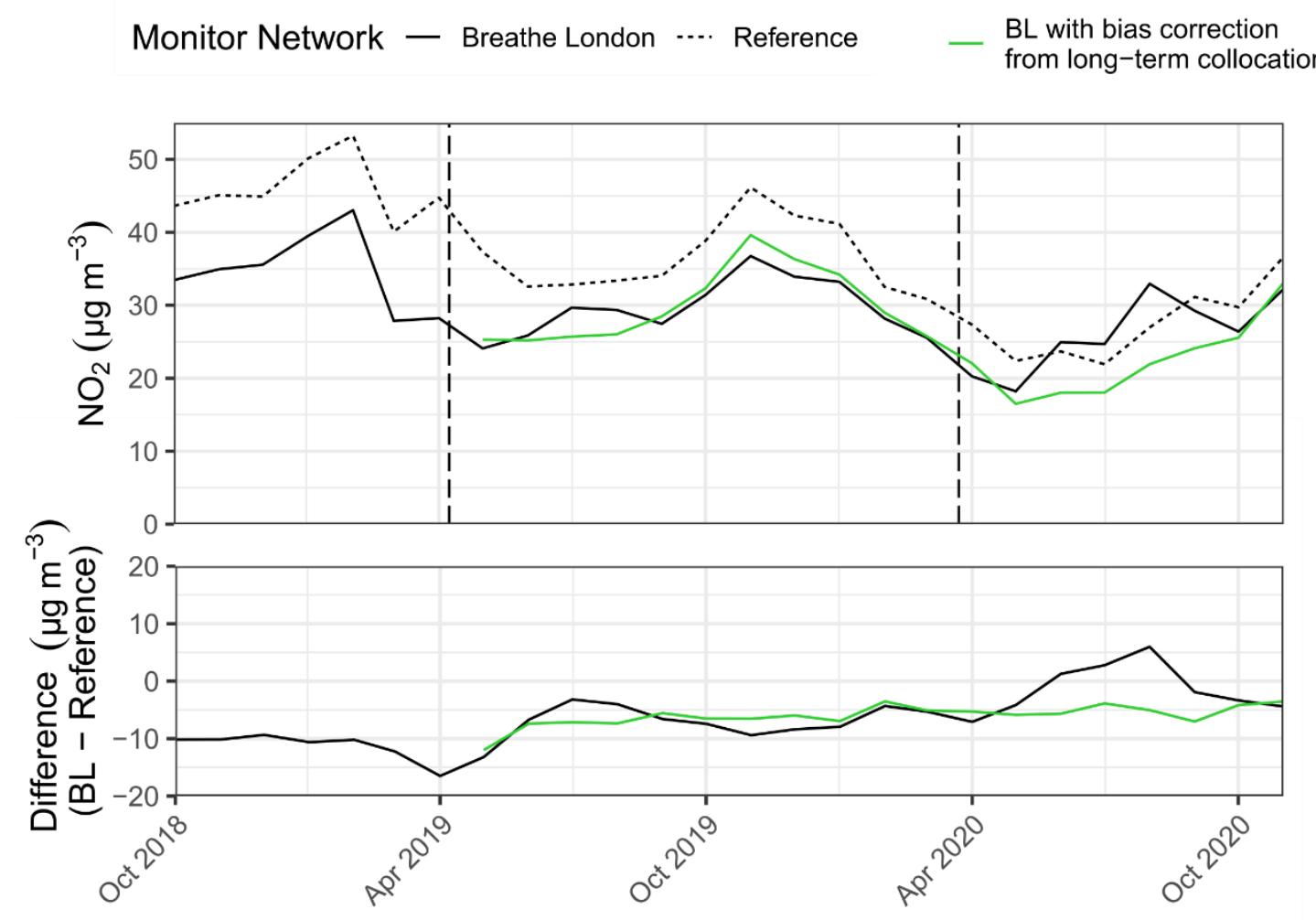

Figure S10: Network monthly mean timeseries comparing BL $(\mathrm{n}=100)$ and London reference $(\mathrm{n}=105)$ networks. Bottom panel shows difference between networks. Vertical lines denote Ultra Low Emission Zone (ULEZ) start date (8 April 2019) and the start of the first Covid-19 lockdowns (23 March 2020). This is the same as Fig. 4 except green solid line shows corrected BL data that was offset using the monthly average sensor bias during the two long-term collocations (Fig. 3b). 


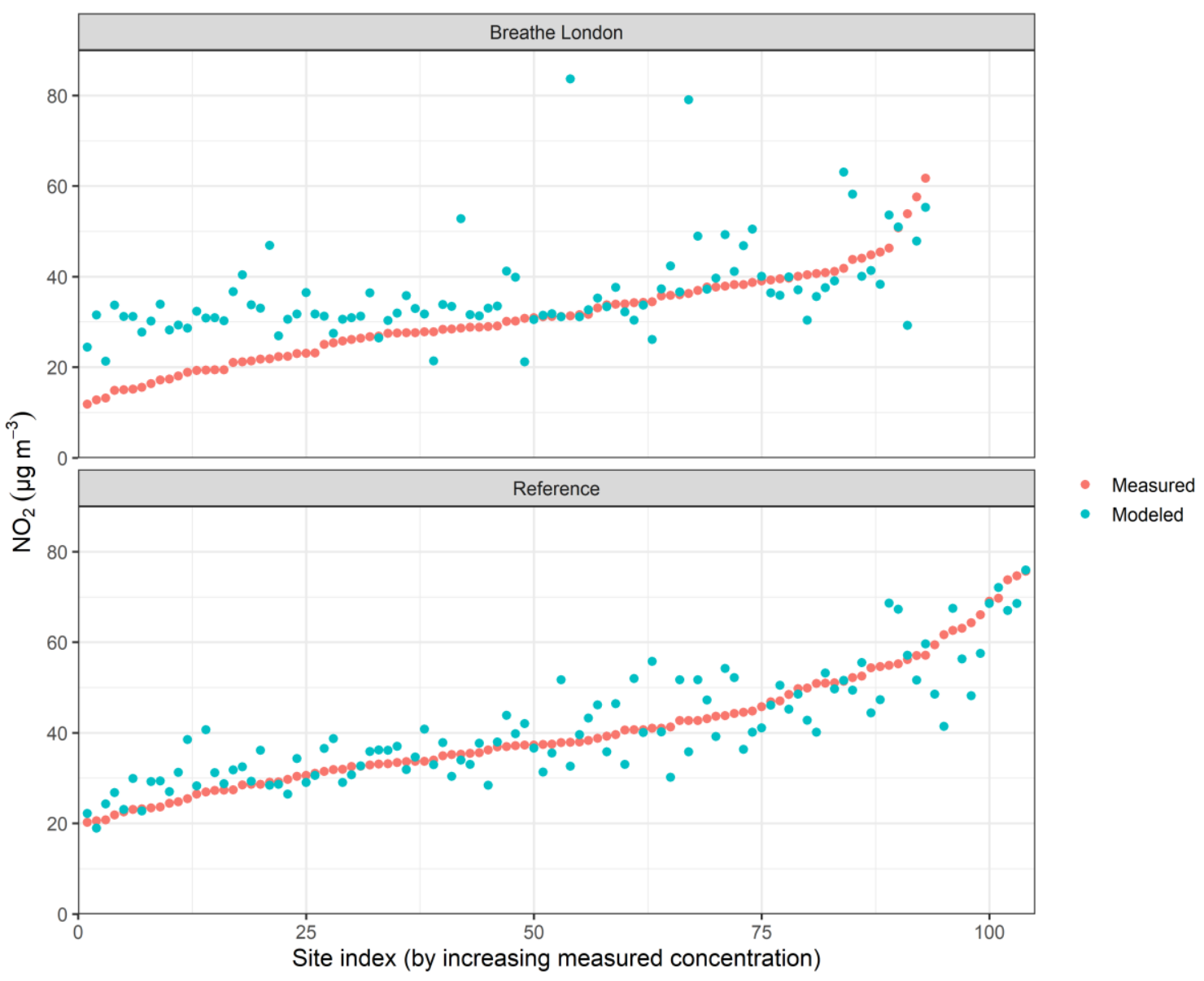

Figure S11: Comparison of modeled (ADMS-Urban) and measured 2019 annual mean $\mathrm{NO}_{2}$ concentrations at BL (top) and reference (bottom) network monitors. All hourly pairs of valid modelled and observed concentrations were analyzed.

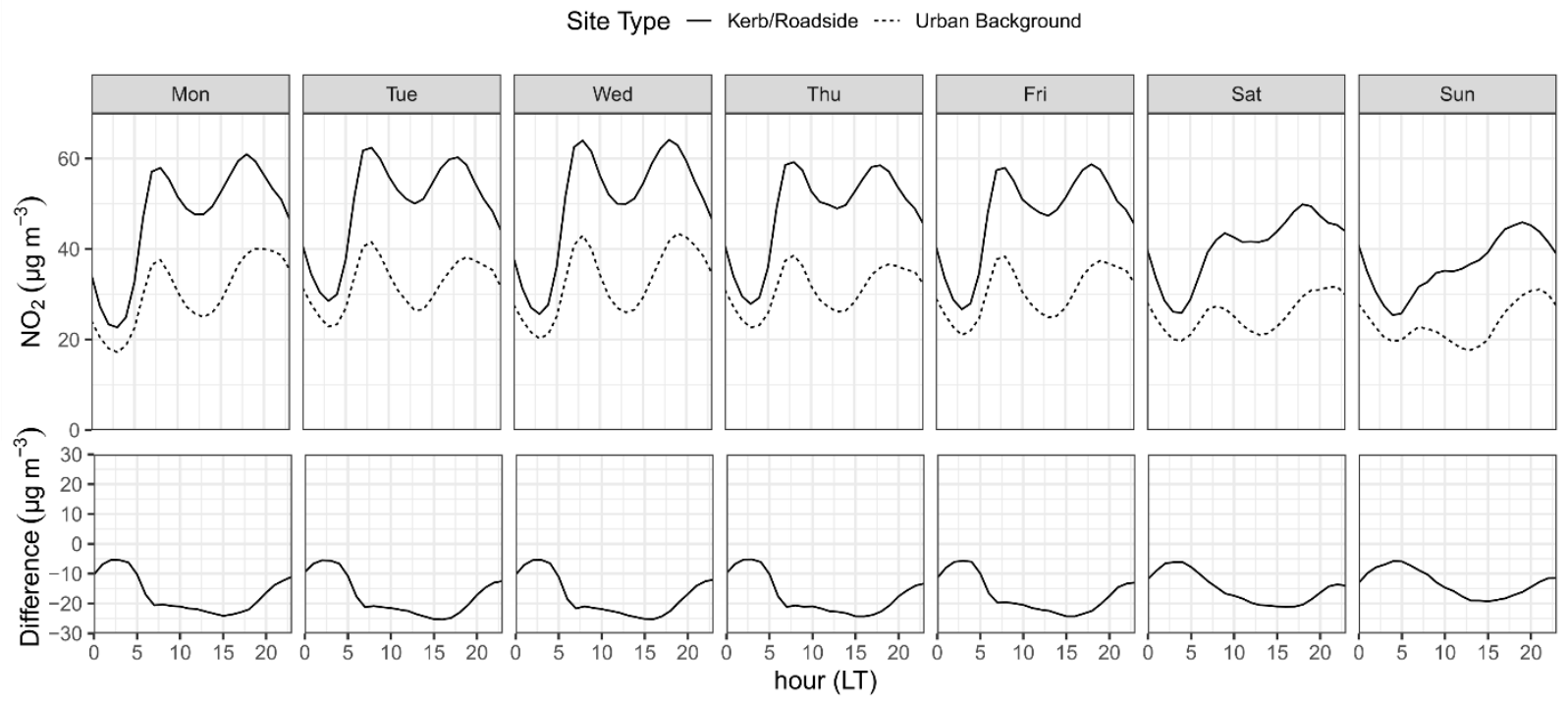

Figure S12: Network mean diurnal and day-of-week $\mathrm{NO}_{2}$ concentration patterns in Greater London in reference network, as measured at near-road $(n=74$; roadside $\&$ kerbside sites) and urban background $(n=31)$ sites during the pre-Covid-19 period of the BL project (1 Oct 2018 through 29 Feb 2020). Bottom panel shows difference between site types (urban background - nearroad). 


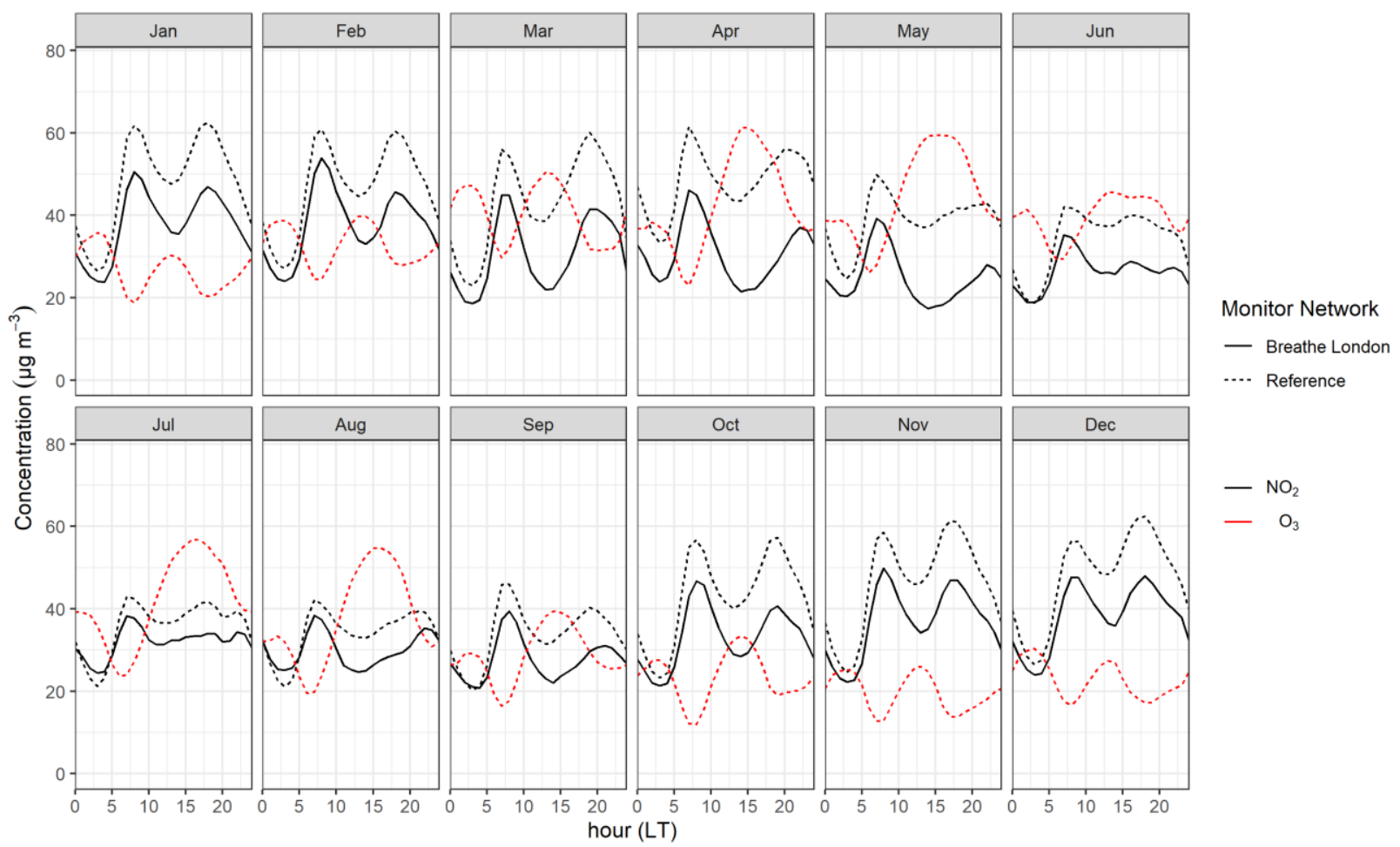

Figure S13: Weekday diurnal mean $\mathrm{NO}_{2}$ and $\mathrm{O}_{3}$ concentrations in Greater London as measured by $\mathrm{BL}\left(\mathrm{n}=99 \mathrm{NO}_{2}\right)$ and reference $\left(\mathrm{n}=105 \mathrm{NO}_{2} ; \mathrm{n}=18 \mathrm{O}_{3}\right)$ networks during the pre-Covid-19 period of BL (1 Oct 2018 through $\left.29 \mathrm{Feb} 2020\right)$. The figure indicates that the BL network measures a lower peak in the afternoon compared to the morning during most months of the year, and the irregularity does not appear to be related to ozone cross-interference.

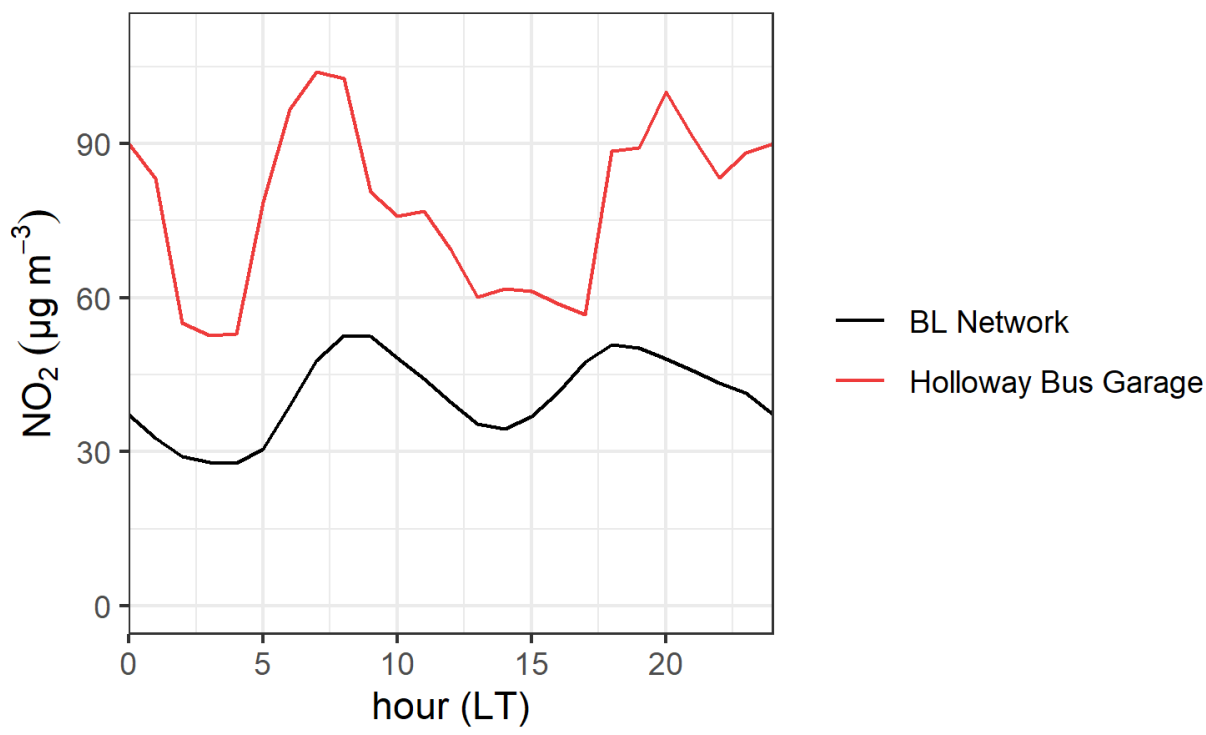

Figure S14: Weekday diurnal mean concentrations at Holloway Bus Garage BL location compared to the mean across the rest of the BL network ( $\mathrm{n}=68)$ during 1 December 2018 through 28 February 2019. 


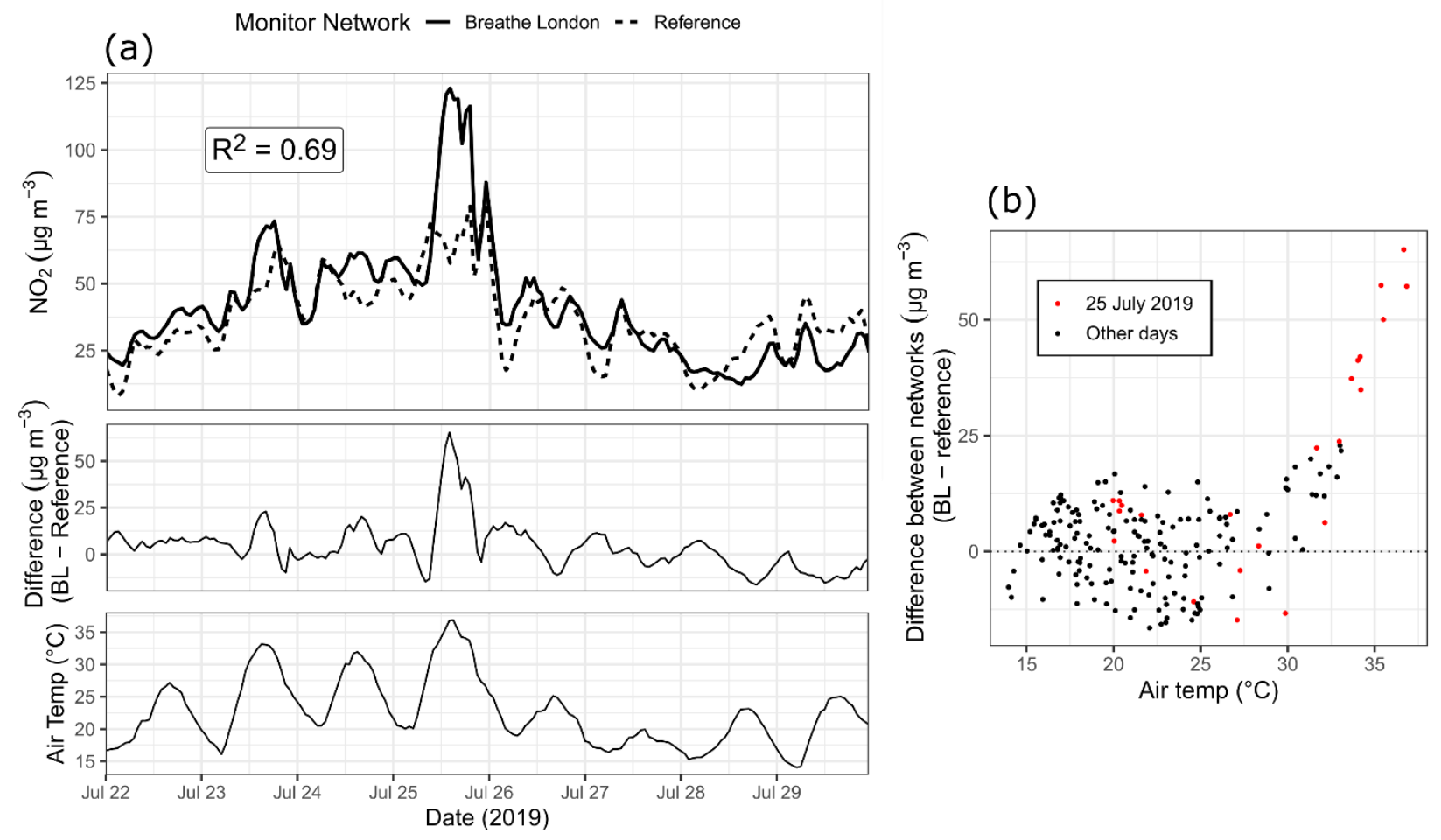

Figure S15: (a) Hourly network mean $\mathrm{NO}_{2}$ concentrations for $\mathrm{BL}(\mathrm{n}=93)$ and reference $(\mathrm{n}=103)$ networks during a high-pollution episode in July 2019. Middle panel shows difference between networks. Bottom panel shows ambient air temperature $\left({ }^{\circ} \mathrm{C}\right)$ at London Heathrow Airport. (b) Scatter plot of the difference between networks each hour compared to the ambient air temperature $\left({ }^{\circ} \mathrm{C}\right)$ at London Heathrow Airport. 